\title{
A Matlab based Graphical User Interface for Computing Optimal Diet of People Living with HIV at Asyptomatic Stage
}

\author{
Yasin Kaunda Kowa \\ The Nelson Mandela African \\ Institution of Science and \\ Technology (NM-AIST) \\ P.O. Box 447, \\ Arusha, Tanzania
}

\author{
Emmanuel Mpolya \\ The Nelson Mandela African \\ Institution of Science and \\ Technology (NM-AIST) \\ P.O. Box 447, \\ Arusha, Tanzania
}

\author{
Yaw Nkansah-Gyekye \\ The Nelson Mandela African \\ Institution of Science and \\ Technology (NM-AIST) \\ P.O. Box 447, \\ Arusha, Tanzania
}

\begin{abstract}
Achieving basic nutritional recommendations for people living with HIV is important at all stages as the virus affects the immune system and renders an infected person to contract other infections easily. Poor nutrition strengthens the effects of HIV as malnutrition adds to deterioration of the immune system. This leads to a poor prognosis of the disease. Thus a tool to determine adequate amount and good combination of different available foods that ensures optimal nutrients will prove useful if designed. In this paper, a MATLAB based Graphical User Interface (GUI) that will be used to compute adequate amount of foods which will lead to the achievements of recommended nutrient intakes for these patients has been developed. The design and use of a GUI can be extended to various telecommunication devices and be accessible to a normal person and other groups in needs of diet management and therefore it will have a wider application.
\end{abstract}

\section{Keywords}

MATLAB, Graphical User Interface, HIV, optimal diet, computing

\section{INTRODUCTION}

It is important that people living with HIV (PLWHIV) keep their bodies as healthy as possible by making sure that they get all the nutrients a person needs as HIV affects their immune systems making them susceptible to opportunistic infections [3]. The effects of HIV are worsened by poor nutrition which contributes to the deterioration of the immune system [17]. A healthy and balanced diet will help to maintain and improve the performance of the immune system for the body's protection against infection and therefore helps a person stay healthy [1].

PLWIHV have additional requirements of energy compared to non-infected persons. An adult with early infection (asymptomatic stage) needs $10 \%$ to $20 \%$ of extra energy while at symptomatic stage needs $20 \%$ to $30 \%$ extra energy above the recommended daily/dietary intake (RDI) compared to a noninfected adult of the same age and sex. Children with early infection (asymptomatic stage) require 10\%, and 20\% to $30 \%$ extra energy at symptomatic stage compared to a non-infected child of the same age and sex. There is no strong evidence to suggest that HIV infection increases protein, vitamins and minerals requirements above the RDI of the non-infected individuals [13 and 17]. In this paper, PLWHIV who are at early stages of infection (asymptomatic stage) have been con- sidered since at this stage their weights are equivalently to the non-infected (normal) people of the same age, height and sex and we want them to maintain their healthy status.

A graphical user interface (GUI) is a graphical display in one or more windows containing controls, called components, which enables a user to perform interactive tasks [4 and 6]. The user of the GUI does not have to create a script or type commands at the command line to accomplish the tasks and need not understand the details of how the tasks are performed. Using MATLAB programming language one can create a GUI which contains controls such as menus, toolbars, buttons and sliders [4, 6 , and 18$]$.

This paper aims to develop a MATLAB based graphical user interface that will enable people living with HIV to compute the adequate amount of foods that will meet the optimal nutrients (nutritional recommendations) required in their bodies. In the absence of cure this will help better manage their health and continue having important contributions to social and economic sectors at the household and national levels.

\section{RESEARCH METHODOLOGY}

In this paper, a MATLAB based Graphical User Interface (GUI) has been developed by GUIDE (graphic user interface development environment) method. To achieve the goal intended, codes that combine multiple linear regression model and a linear programming model, and a two phase simplex method algorithms are added in the function computation_callback. A two phase simplex method will be used to compute the adequate amount of foods from a mathematical model incorporated in the GUI. The food composition table for the list of foods in the GUI has been suggested by [13].

\section{MATHEMATICAL MODEL FORMULATION}

The mathematical model combines multiple linear regression and linear programming models; the regression model uses the factors age, weight, height and gender to capture and predict the nutritional needs in the body. The results from the multiple linear regression model defines/limits the constraints in the linear programming model we have set. The constraints are restricted to minimum amount of nutrients required and maximum allowable amount of nutrients but also the maximum allowable amount of food. 


\subsection{Regression analysis}

According to [11] and [16] who corrected [10], for a multiple linear regression analysis (model) to be valid, four assumptions need to be met; these include normality of errors (residuals), linearity of parameters in the model, assumptions about the model error and assumption about measurement error (reliability).

\subsubsection{Normality of errors or residuals}

Here it is assumed that errors are normally distributed in any combination of values on the predictor variables. The properties of the errors are investigated by calculating the residuals of a regression model in the sample data. It should be noted that it is not necessary for predictors to be normally distributed [11 and 16].

\subsubsection{Linearity of parameters in the model}

This means that the response variable is assumed to be a linear function of parameters such as $\beta_{0}, \beta_{1}, \beta_{2}, \beta_{3}, \ldots, \beta_{p}$ but not necessarily a linear function of the predictor variables $\mathrm{X}_{1}, \mathrm{X}_{2}, \mathrm{X}_{3}, \ldots, \mathrm{X}_{\mathrm{p}}[11,12$, and 16].

\subsubsection{Assumptions about the model error}

According to [2,11, 15 and 16 in 14] this assumption include means of errors should be zero, independence of error, homoscedasticity, that is constant variance of errors and normal distribution of errors as has been named and explained above.

\subsubsection{Assumption about measurement error (reliability)}

The assumption assumes that predictor variables are measured without errors, error in the response variable are considered not harmful to inferences related to unstandardized regression confidents, provided this measurement error is not correlated with the predictor variable value [10,11 and 16].

Apart from the four assumptions above, the regression analysis has considered factors such as measure of goodness of fit $\mathrm{R}^{2}$, and the significance of the model and coefficients.

From the regression analysis of each nutrient as a response variable on explanatory variables age (A), weight $(\mathrm{W})$, height $(\mathrm{H})$ and gender $(\mathrm{G})$, the result was as follows;

$$
\begin{gathered}
\mathrm{RDI}_{\text {Energy }}=0.002 \mathrm{~A}^{3}-19.773 \mathrm{~A}+14.399 \mathrm{~W}+18.367 \mathrm{H} \\
+178.263 \mathrm{G}-753.860
\end{gathered}
$$

$$
\begin{aligned}
& \mathrm{RDI}_{\text {Niacin }}=2.434 \mathrm{E}-6 \mathrm{~A}^{3}-0.001 \mathrm{~W}^{2}+0.001 \mathrm{H}^{2}-0.107 \mathrm{H}+8.002 \\
& \mathrm{RDI}_{\text {Vitamin B6 }}=7.226 \mathrm{E}-7 \mathrm{~A}^{3}-1.334 \mathrm{E}-6 \mathrm{~W}^{3}+0.023 \mathrm{~W}+0.192 \\
& \mathrm{RDI}_{\text {Folate }}=17.576 \mathrm{~W}-0.133 \mathrm{~W}^{2}-5.220 \mathrm{H}+0.014 \mathrm{H}^{2}+303.834 \\
& \mathrm{RDI}_{\text {Vitamin B12 }}=0.063 \mathrm{~W}-4.486 \mathrm{E}-6 \mathrm{~W}^{3}-0.006 \mathrm{H}+0.696 \\
& \mathrm{RDI}_{\text {Pantothenc }}=1.680 \mathrm{E}-6 \mathrm{~A}^{3}+3.925 \mathrm{E}-5 \mathrm{~W}^{3}-0.004 \mathrm{~W} \\
& +1.698 \mathrm{E}-6 \mathrm{H}^{3}+0.451 \mathrm{G}+2.649 \\
& \mathrm{RDI}_{\text {Phosphorus }}=-0.005 \mathrm{~W}^{3}+0.253 \mathrm{H}^{2}-42.095+2169.802 \\
& \mathrm{RDI}_{\text {Potassium }}=252.852 \mathrm{In} \mathrm{A} 88.411 \mathrm{~W}+0.007 \mathrm{~W}^{3}+0.160 \mathrm{H}^{2} \\
& +283.435 \mathrm{G}+1474.871 \\
& \mathrm{RDI}_{\text {Sodium }}=14.035 \mathrm{~W}-0.108 \mathrm{~W}^{2}+5.548 \mathrm{H}-0.017 \mathrm{H}^{2}-204.433 \\
& \mathrm{RDI}_{\mathrm{Zinc}}=5.451 \mathrm{E}-6 \mathrm{~A}^{3}+6.699 \mathrm{E}-5 \mathrm{~W}^{3}-0.579 \mathrm{~W}+0.248 \mathrm{H}-12.172 \\
& \mathrm{RDI}_{\text {Copper }}=0.136 \mathrm{In} \mathrm{A}+4.568 \mathrm{E}-6 \mathrm{~W}^{3}-0.051 \mathrm{~W}+0.022 \mathrm{H}+0.128 \mathrm{G} \\
& \mathrm{RDI}_{\text {UpperVitamin E }}=12.965 \mathrm{~W}-0.042 \mathrm{~W}^{2}-6.522 \mathrm{E}-5 \mathrm{H}^{3}-43.248 \\
& \mathrm{RDI}_{\text {UpperNiacin }}=2.989 \mathrm{InA}+0.311 \mathrm{~W}+3.512 \\
& \mathrm{RDI}_{\text {UpperVitamin B6 }}=3.419 \mathrm{In} \mathrm{A}+1.383 \mathrm{~W}-6.155 \mathrm{E}-5 \mathrm{~W}^{3}-0.389 \mathrm{H} \\
& +30.112
\end{aligned}
$$

$\mathrm{RDI}_{\text {UpperFolate }}=41.284 \mathrm{InA}+40.128 \mathrm{~W}-0.154 \mathrm{~W}^{2}-0.043 \mathrm{H}^{2}$

$$
\begin{array}{r}
\mathrm{RDI}_{\text {UpperSodium }}=129.946 \mathrm{InA} 0.157 \mathrm{~W}^{2}+0.074 \mathrm{H}^{2}+354.670 \\
\mathrm{RDI}_{\text {Upper Zinc }}=1.461 \mathrm{~W}-6.195 \mathrm{E}-5 \mathrm{~W}^{3}-6.192 \mathrm{E}-6 \mathrm{H}^{3}-7.164 \\
\mathrm{RDI}_{\text {Upper Copper }}=0.805 \mathrm{InA}+0.312 \mathrm{~W}-1.484 \mathrm{E}-5 \mathrm{~W}^{3}-0.074 \mathrm{H} \\
+3.286
\end{array}
$$

\subsection{Linear programming model}

Linear programming model involves food items as the variable $x_{i}$, parameter cost of food $i$ as $c_{i}$, the nutrient $j$ contained in food $\mathrm{i}$ is given as $\mathrm{A}_{\mathrm{ji}}, \mathrm{b}_{1}$ the maximum allowable amount of nutrient $j, b_{2}$ the minimum amount of nutrient $j$ required and $F_{\max } i$ the maximum allowable amount of food $i$. From the multiple linear regression model, $b_{1}$ and $b_{2}$ are defined as $b_{1}=\left\{R D I_{\text {max } j}\right\}, b_{2}=\left\{R D I_{\text {min } j}\right\}$ where $R D I_{\text {min } j}$ the regression model for minimum recommended amount of 
nutrient $\mathrm{j}$ and $\mathrm{RDI}_{\max \mathrm{j}}$ the regression model for maximum recommended amount of nutrient $j$. Mathematically this is written as

$$
\begin{aligned}
& \operatorname{minimize} \sum_{\mathrm{x}_{\mathrm{i}}} \mathrm{x}_{\mathrm{i}} \mathrm{c}_{\mathrm{i}} \\
& \text { subject to } \mathrm{A}_{\mathrm{ij}} \leq \mathrm{b}_{1} \\
& \mathrm{~A}_{\mathrm{ij}} \geq \mathrm{b}_{2} \\
& \mathrm{x}_{\mathrm{i}} \leq \mathrm{F}_{\operatorname{maxi}} \\
& \mathrm{x}_{\mathrm{i}} \geq 0
\end{aligned}
$$

\section{GRAPHICAL USER INTERFACE DEVELOPMENT}

A Graphical User Interface (GUI) in MATLAB has been developed by the GUIDE method, GUIDE enables the rapid creation of a graphical user interface (GUI) for a MATLAB program [6, 7 and 8]. The two phase simplex method which is used for computing the adequate amount of foods from the mathematical model uses the totbl and $l j x$ codes [5 and 9]. The totbl displays the tableau while the ljx exchange the pivot column and pivot row. In order to achieve the intended goal, these codes are extended so that it identifies the pivot column and pivot row automatically but originally the pivot row and column were identified manually, also the extended codes displays the answer to the GUI automatically rather than reading from the tableau. The result from the two phase simplex method will either be optimal or not optimal, whatever the result obtained the user will be notified.

The GUI has five major parts: the first is the list of foods which contain a variety of foods that the user will choose. To select multiple foods she/he need to press the control button on keyboard while the mouse click on the foods she/he want to eat.

The second part is to enter her/his particulars: these are the age in years, weight in kilograms, height in centimeters, and gender where men have to enter 1 while women enter 0 ; note that 1 and 0 are arbitrary. Once she/he enters her/his particulars the mathematical model captures and predicts her/his nutrients requirement in the body. The third part is to enter the cost of each food that has been chosen (the cost should be per kilogram) and there should be a space between the costs.

The fourth is the computation part; after the first three parts the user has to click the compute button for computation to take place. After computation the status box will state whether her/his selection is optimal or not, if is optimal means she/he can take that combination but if not optimal she/he need to look for another combination, but need to reset by clicking the reset button before starting the computation again. The reset button clears the previous inputs and results.

The last part is the see the results; this contains the index of food component which display the index of foods which should be bought and the amount component indicates what amount of foods in kilograms she/he need to buy. Then the total cost component gives the total cost that will be incurred on buying these foods. But note that the index of foods will be $\mathrm{x}_{1}$ for the first food that has been chosen, $\mathrm{x}_{2}$ for the second food chosen, and so on up to $\mathrm{x}_{\mathrm{n}}$ for the last food selected. The last part will happen if and only if the computation is optimal. The GUI developed looks like in Figure 1 below.

\subsection{Illustration}

Suppose there are ten foods which are easily found in a certain area, these foods are rice with coconut milk, banana with meat and coconut milk, beef, avocado, papaya juice, spinach, donut African, cassava porridge, fish dried fresh water and salad green whose estimated costs per kilogram are $(2000$, 2500, 6000, 700, 1500, 600, 1000, 1000, 7000, 500) Tanzania shillings (TSH) respectively. From this list an individual can select what to eat, the GUI help individuals to compute amount of foods that will lead to achievement of nutritional recommendation, for instance a man whose age is 40.5 years, weighing $69.7 \mathrm{~kg}$ and height of $176 \mathrm{~cm}$ decided to select all foods then after computation to take place the GUI will look like in Figure 2 below.

From Figure 2 the man aged 40.5 years, weighting $69.7 \mathrm{~kg}$ and of height $176 \mathrm{~cm}$ has selected ten foods, submitted his particulars and cost of foods selected. The computation shows that the selection is optimal as seen on status component and he need to buy $0.25 \mathrm{~kg}$ of rice with coconut milk, $0.25 \mathrm{~kg}$ of banana with meat and coconut milk, approximately $0.081 \mathrm{~kg}$ of beef, $0.15 \mathrm{~kg}$ of avocado, approximately $0.169 \mathrm{~kg}$ of spinach, $0.2 \mathrm{~kg}$ of donut African, $0.2 \mathrm{~kg}$ of cassava porridge, 0.25 $\mathrm{kg}$ of fish dried fresh water and $0.15 \mathrm{~kg}$ of salad green. But also we see that he should not buy papaya juice in order to meet the recommended nutrients because do not appear in the see the results part. The total cost that will be incurred for buying these foods is TSH 4,044.79.

Figure 3 below shows that nine foods have been selected by a man aged 40.5years, weighing $69.7 \mathrm{~kg}$, and of height $176 \mathrm{~cm}$. The cost of foods selected have been submitted. The computation shows that the selected combination is not optimal as stated in the status component. But also there is no results in the See the Results component. This means that he should not take such combination otherwise the recommended nutrients will not be met.

\section{CONCLUSION AND DISCUSSION}

Meeting the recommended nutrients for PLWHIV is vital as it will help to maintain and improve the performance of the immune systems. This will protect them from contracting other diseases easily. The study has developed a MATLAB based Graphical User Interface that gives opportunity to PLWHIV to compute adequate amount of foods that will meet the recommended nutrients. The GUI asks the user to enter their age, weight, height and gender in order to predict their nutrient requirements, select the foods they want to eat, to submit the cost of each food of their choice. This will accommodate the fact that the cost of foods is always dynamic.

The GUI will give back the index of foods to be bought, amount of foods to be bought and the total cost that will be incurred to buy all foods, provided such combination is optimal. If the combination is not optimal there will be no results in the See the Results component and it will be stated that not optimal on the status component.

The study may be limited to the index of foods rather than real names, this may lead to misinterpretation. This could be adjusted in future towards a more comprehensive and userfriendly system. Also, currently the access of the GUI is limited and this will be improved in future through development of a web page or a mobile application which will be easily accessed. 
- GRAPHICAL USER INTERFACE FOR COMPUTING OPTIMAL DIET
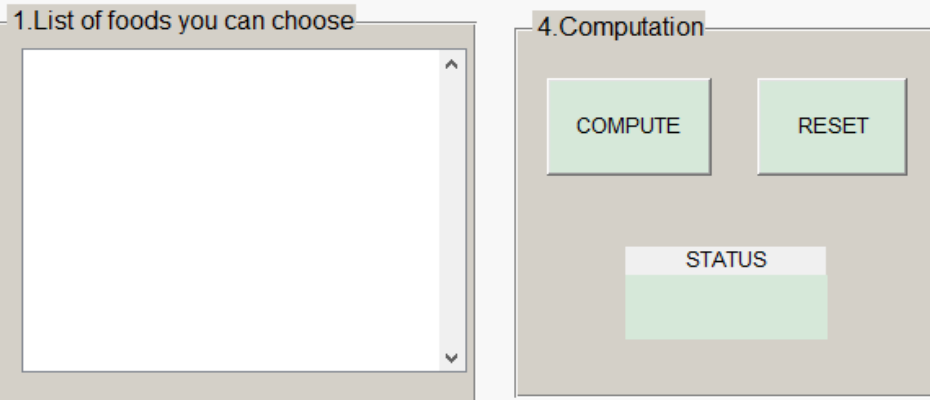

2.Enter your particulars

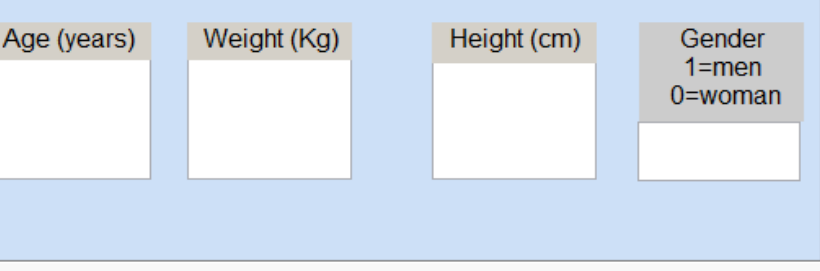

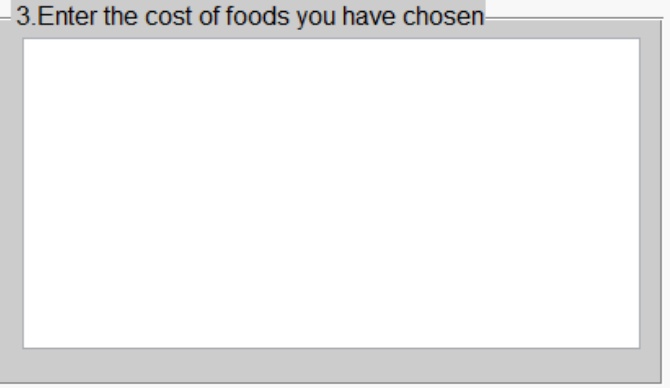

-5 . See the Results

Index of food Amount of food Total cost of foods $(\mathrm{Kg})$
(Tsh)

Figure 1: Graphical user interface for computing optimal diet. The steps to be taken are ordered from numbers 1 to 4 . The client selects foods she/he wants to eat from the list given (step 1). Then proceeds to enter his/her particulars (age, weight, height and gender) - step 2- and the costs of the foods selected (step 3). The client then proceeds to compute (step 4) and obtains the output (step 5)

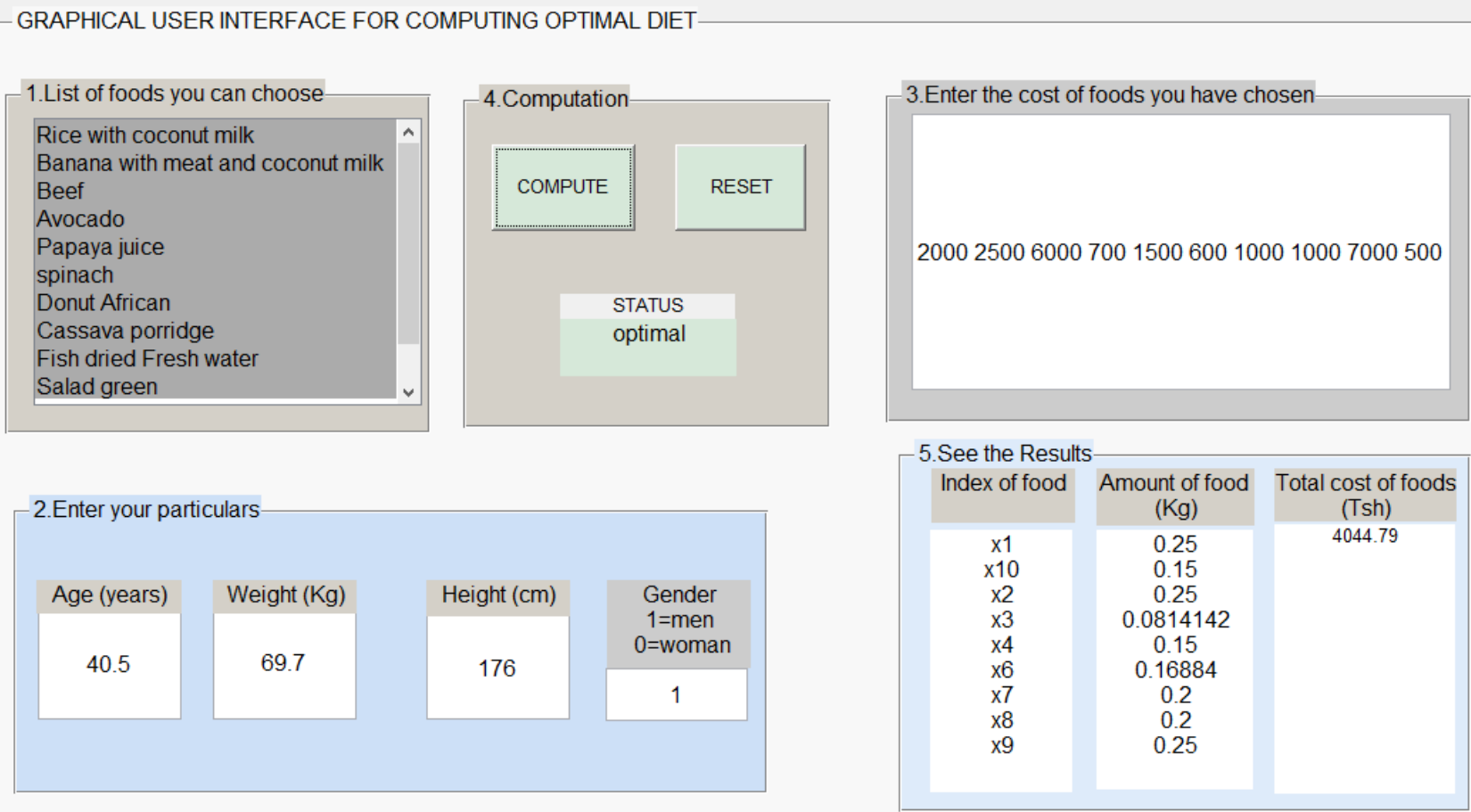

Figure 2: Illustration of GUI computation 


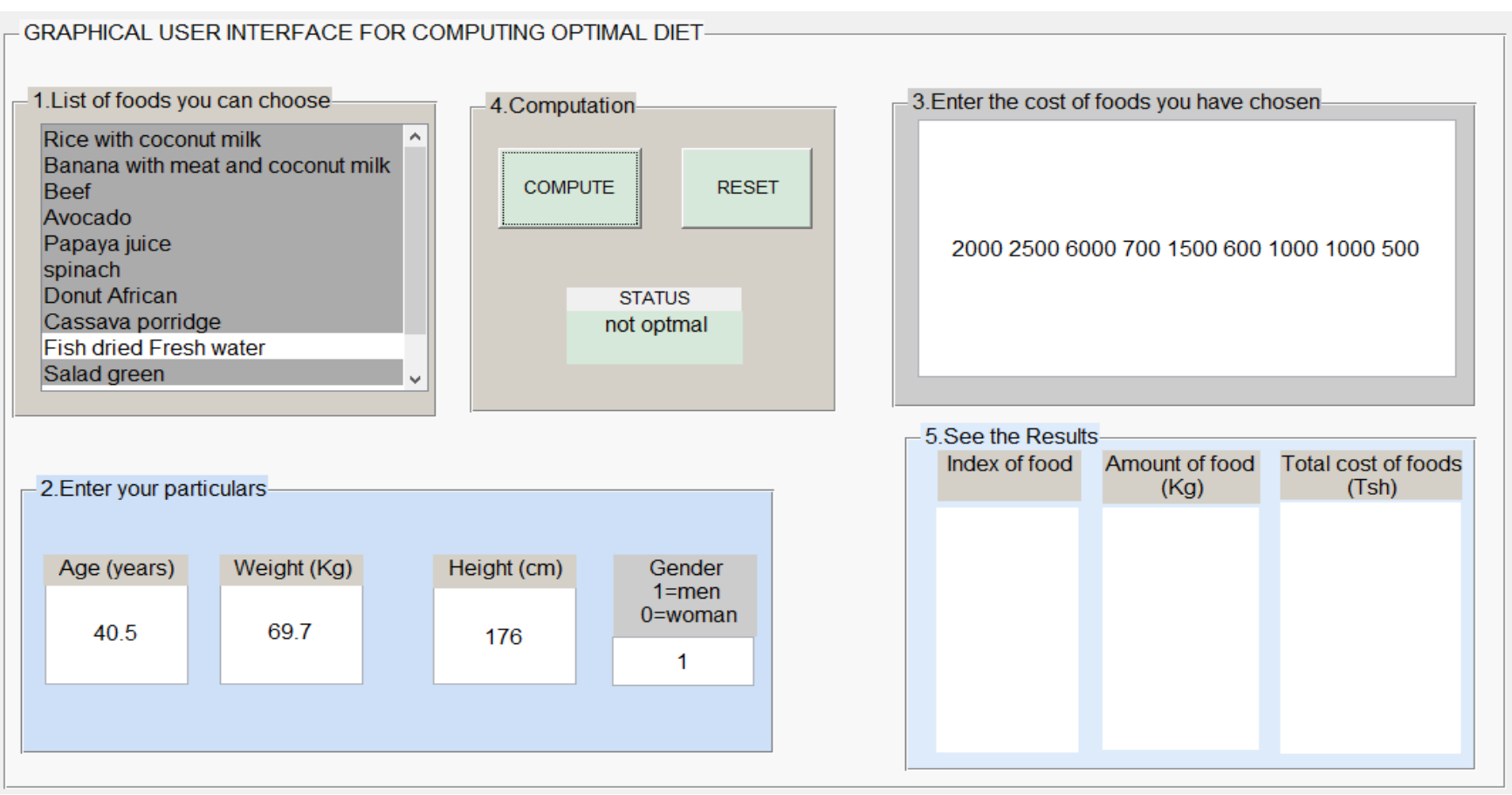

Figure 3: Illustration of GUI computation

\section{REFERENCES}

[1] Akram, D.-S., Bagchi, K., Becker, G., Bhandari, N., Bland, R., Brandes, N. and Z. Brazdova. 2003. Cecilia Acuin. Special Issue Based on a World Health Organization Expert Consultation on Complementary Feeding 24:130.

[2] Chatterjee, S., and Hadi, A. S. 2013. Regression analysis by example. John Wiley \& Sons,

[3] Clark, R.A., Maupin Jr, R. T. , Hayes, J. and Hammer, J. H. 2012. A woman's guide to living with HIV infection. JHU Press,

[4] Guruhappa, H., Sree, S., Madhu, C. and Srivastava, K. 2013. A Graphical User Interface (GUI) in MATLAB to Compute the Thermal Lithospheric Thickness and its Error Bounds. interface 10:11.

[5] Michael C. Ferris, Olvi L. Mangasarian, Stephen J. Wright.Linear Programming with Matlab, http://research.cs.wisc.edu/math-prog/lpbook/

[6] Hunt, B. R., Lipsman, R. L. and Rosenberg, J. M. 2014. A guide to MATLAB: for beginners and experienced users. Cambridge University Press,

[7] Kumar, A., Kamboj, D., Choudhary, J., Yadav, N. and Batra, V. GUI Based Device Controller Using MATLAB

[8] Lent, C. S. 2013. Learning to Program with MATLAB: Building GUI Tools: Building GUI Tools. Wiley Global Education,

[9] Michael C. Ferris, O.L.M., Stephen J. Wright. 2008. Linear Programming with MATLAB. Society for Industrial and Applied Mathematics,
[10] Osborne, J., and Waters, E. 2002. Four assumptions of multiple regression that researchers should always test. Practical assessment, research \& evaluation 8:1-9.

[11] Poole, M. A., and O'Farrell, P. N.. 1971. The assumptions of the linear regression model. Transactions of the Institute of British Geographers 145-158.

[12] Seber, G. A., and Lee, A. J. 2012. Linear regression analysis. John Wiley \& Sons,

[13] Tanzania Food and Nutrition Center (TFNC), 2009. National guidelines for nutrition care and support for people living with HIV in Tanzania, Tanzania Food and Nutrition Center, Dar es Salaam.

[14] Weisberg, S. 2005. Applied linear regression. John Wiley $\&$ Sons,

[15] Weisberg, S. 2014. Applied linear regression. John Wiley \& Sons,

[16] Williams, M. N., Grajales, C. A. G., and Kurkiewicz, D. 2013. Assumptions of multiple regression: correcting two misconceptions. Pract. Assess. Res. Eval 18:

[17] World Health Organisation (WHO). 2007. Nutrient requirements for people living with HIV/AIDS: report of a technical consultation; 2003. In.

[18] Yang, Q.-M., Lee, Y.-S., Lee, E.-Y., Kim, J.-H., Cha, K.U., and Hong, S.-K. 2009. A residual stress analysis program using a Matlab GUI on an autofrettaged compound cylinder. Journal of mechanical science and technology 23:2913-2920. 